\title{
A CONSTRUÇÃO DO \\ TRABALHO DE CONCLUSÃO DO CURSO POR MEIO DA METODOLOGIA ATIVA TEAM-BASED LEARNING
}

\author{
DEVELOPING FINAL COURSE MONOGRAPHS USING A \\ TEAM-BASED LEARNING METHODOLOGY
}

\author{
Recebido em: 18/09/2015• Aprovado em: 03/12/2015 \\ Avaliado pelo sistema double blind review \\ Editora Científica: Cláudia de Salles Stadtlober \\ DOI: $10.13058 /$ raep.2016.v17n1.274
}

\author{
ANI MARI HARTZ ani.hartz@espm.br \\ GABRIEL VIANNA SCHLATTER \\ ESCOLA SUPERIOR DE PROPAGANDA E MARKETING - SUL
}

\begin{abstract}
RESUMO
Este artigo tem como objetivo principal descrever a experiência de uso da metodologia ativa Team-Based Learning (TBL) (aprendizagem baseada em equipes) em disciplinas de apoio ao planejamento e execução de trabalhos de conclusão de curso, contendo tanto as percepções dos professores quanto a avaliação dos alunos. Para empreender essa pesquisa, utilizou-se a vertente qualitativa, por meio das técnicas de observação e de pesquisa bibliográfica, e a vertente quantitativa, de caráter conclusivo, por meio de questionário. A amostra foi de 49 alunos, sendo 27 deles pertencentes ao curso de Publicidade e Propaganda e 22 ao curso de Administração de Empresas de uma instituição de ensino superior. A análise dos dados qualitativos foi feita por meio de uma categorização simples, com categorias definidas a posteriori. A análise dos dados quantitativos foi feita por meio de estatística descritiva e análise de conglomerados, utilizando-se o software Minitab i7.I. Dentre os principais achados destacam-se a identificação de três perfis de alunos (designados como tradicional, colaborativo e prático); a preferência destes por uma orientação e um feedback do professor no lugar do colega; e a necessidade de fechamento da aplicação do método, realizado pelo professor. Como benefícios diretos ao aluno, estes reconheceram que a discussão no grupo permitiu ter consciência sobre o quanto realmente sabiam sobre o assunto estudado. Por fim, a maioria manifestou ter gostado da abordagem Team-Based Learning (TBL).
\end{abstract}

Palavras-chave: metodologias ativas; aprendizagem baseada em equipes; trabalho de conclusão de curso; ensino e aprendizagem.

\begin{abstract}
This article describes an experience with the Team-Based Learning (TBL) methodology in courses designed to support the planning and execution of final course monographs. It contains both professors' and students' perceptions, through observation and assessment. A qualitative approach using observation techniques and desk research was used in conjunction with a quantitative approach based on a questionnaire. The sample consisted of 49 students from a higher education institution, 27 of them in a Communication Course and the remaining 22 in a Business Administration course. Qualitative data analysis was performed through simple categorization with back-defined categories, while the quantitative data analysis employed descriptive statistics and cluster analysis using Minitab 17.1 software. The main findings include the identification of: three student profiles (designated as traditional, collaborative and practical); a preference for guidance and feedback from the professor rather than other students; and a need for a professor-led closing discussion when applying the TBL method. As regards the main benefits to students, they recognized that discussion in groups allowed them to realize how much they really know about the subject studied. Finally, most students seemed to like the TBL approach. Keywords: active methodologies; team-based learning; final course monograph; teaching and learning.
\end{abstract}




\section{INTRODUÇÃO}

O sistema educacional tradicional nas universidades brasileiras é, essencialmente, baseado no professor, o qual tem como o objetivo transferir o seu conhecimento para os alunos e avaliar o nível de conhecimento adquirido (TeIXeIRA, 1985). De acordo com Mizukami (I986, p. II) “[...] atribui-se ao sujeito um papel irrelevante na elaboração e aquisição do conhecimento. Ao indivíduo que está "adquirindo" conhecimento compete memorizar definições, enunciados de leis, sínteses e resumos que lhe são oferecidos no processo de educação formal", sendo mais comum o formato de aula expositiva. É importante destacar, entretanto, que as pessoas são diferentes e, como consequência, as maneiras de perceber, entender e processar as informações também são distintas. Dunn (1990), por exemplo, defende que há estilos de aprendizagem que tratam da forma pelo qual cada indivíduo se concentra, processa e retém uma informação difícil ou nova.

Nessa linha de pensamento, algumas instituições de ensino têm se preocupado com a diversificação das metodologias de ensino utilizadas em sala de aula, procurando explorar esses diferentes estilos de aprendizagem dos alunos. Nesse contexto, o professor pode trabalhar em sua sala de aula com metodologias ativas de ensino e aprendizagem, as quais são centradas no aluno, ao contrário da maioria das metodologias tradicionais utilizadas. Nessa abordagem, o aluno constrói o conhecimento, tendo o professor como um facilitador do processo.

Existem várias metodologias ativas que têm enriquecido as possíveis estratégias pedagógicas, sendo que muitas delas ainda estão sendo estudadas quanto à forma de aplicação e os resultados de aprendizagem. Alguns exemplos dessas metodologias são as técnicas de problematização, o Problema Gerador de Discussão (PGD), o Problem-Based Learning (PBL) e o Team-Based Learning (TBL) (MELO; SANT'ANA, 20I2).

O твL, por exemplo, é uma ferramenta relativamente nova, a qual está baseada no construtivismo e na resolução de problemas. Esta faz com que o aluno seja estimulado a desenvolver, processar, discutir e, como resultado, aumentar a sua capacidade intelectual sobre um determinado assunto, 
sempre na forma de uma dinâmica de equipe (GOPALAN; FOx; GAEBELEIN, 20I3). Trata-se, portanto, de uma abordagem ativa de aprendizagem, centrada no aluno, que instiga a sua curiosidade e que se desenvolve com base no debate de concepções individuais sobre o tema de estudo. A ideia é que o aluno esteja mais motivado tanto para a preparação individual quanto para a construção de conhecimentos por meio do grupo (MICHAELSEN; KNIGHT; FINK, 2002). O TBL pode ser utilizado tanto no ambiente de trabalho quanto no ambiente acadêmico, em qualquer curso e em qualquer disciplina.

Valendo-se desse recurso pedagógico, se procurou identificar situações do contexto do ensino superior onde a sua aplicação pudesse trazer resultados significativos e pertinentes à maior parte dos cursos de formação. Como elemento comum a grande parte dos cursos superiores, se identificou uma experiência que integra a maioria das instituições de ensino superior que é o Trabalho de Conclusão de Curso (TCC). Este é uma exigência formal para a obtenção do diploma em cursos de graduação, a qual busca avaliar o aprendizado global adquirido durante a formação do aluno, bem como sua capacidade de investigar, refletir e fazer novas proposições a respeito de um tema em estudo.

O TCC, portanto, consiste em uma sistematização, registro e apresentação do conhecimento do aluno sobre uma determinada área do curso, tendo um professor que orienta a sua investigação científica (SEVERINO, 2009). Entretanto, essa experiência requer um planejamento prévio, o qual estrutura o processo de pesquisa e de relato por parte do aluno, de modo a validar seus achados com base nos fundamentos do método científico.

Este artigo tem como objetivo principal conciliar esses dois temas, metodologias ativas e trabalho de conclusão de curso, apresentando uma experiência de uso da metodologia Team-Based Learning (TBL) em disciplinas de apoio ao planejamento e execução de trabalhos de conclusão de curso. Além de descrever os experimentos realizados, apresenta a avaliação dos alunos quanto à validade do método, bem como suas percepções em relação à aprendizagem desenvolvida. Os estilos de aprendizagem preferidos pelos alunos também foram analisados, procurando-se identificar perfis característicos de cada grupo que se estabeleceu durante o experimento, bem como da forma como gostariam de utilizar a metodologia TBL. 
O artigo se configura em três partes, além da introdução e das considerações finais. Primeiramente, se apresenta um referencial teórico sobre as metodologias ativas, descrevendo-se, em particular, a metodologia do Team-Based Learning (твL), com base em autores como Michaelsen, Knight e Fink (2002), Gopalan, Fox e Gaebelein (2013) e Simonson (2014). Integra essa parte inicial, um apanhado sobre o Trabalho de Conclusão de Curso, com foco em cursos superiores, tomando-se como referência autores como Neher (2009) e Severino (2009).

$\mathrm{Na}$ segunda parte apresenta-se a estratégia metodológica utilizada para empreender esta pesquisa, a qual é de caráter misto (qualitativo e quantitativo), tendo adotado as técnicas de coleta de dados de pesquisa bibliográfica, observação participante e questionário. De antemão, se apresentam as unidades de estudo da pesquisa, as quais eram representadas por alunos dos cursos de publicidade e propaganda e administração de empresas de uma instituição de ensino superior, totalizando 49 indivíduos participantes.

Por fim, na terceira parte deste artigo, apresentam-se os resultados obtidos, oriundos tanto da observação participante (dados qualitativos) quanto dos questionários aplicados (dados quantitativos). Também integra essa parte a análise estatística realizada sobre os dados coletados e a discussão do que foi obtido à luz da teoria de referência. 


\section{REFERENCIAL TEÓRICO}

A fundamentação teórica deste estudo está baseada no conceito de metodologias ativas, sendo, em particular, explorada a abordagem chamada de Team-Based Learning (TBL) ou Aprendizagem Baseada em Equipes. Assim sendo, se apresentam as concepções associadas às metodologias ativas e se detalha o processo de aplicação do TBL. Além destes pontos, se resgatam os conceitos e objetivos de aprendizagem associados ao trabalho de conclusão de curso, o qual se configurou como o contexto de aplicação da metodologia ativa descrita e sobre o qual se realizaram as pesquisas.

\section{METODOLOGIAS ATIVAS}

O princípio associado ao uso de metodologias ativas consiste em deslocar o eixo principal da responsabilidade pelo processo de aprendizagem do professor para o aluno (MAZUR, 2015). Nesse sentido, o grande objetivo das metodologias ativas é fazer com que o aluno passe a ser o personagem principal da relação de ensino e aprendizagem, sendo que o professor continua participando deste processo, mas o faz com outras formas de contribuição. O Quadro I compara os papeis desempenhados pelo professor e pelo aluno quando a abordagem de ensino está contextualizada em um ambiente que faz uso das metodologias ativas.

Quadro I Papeis do professor e do aluno nas metodologias ativas

\begin{tabular}{|c|c|}
\hline Professor & Aluno \\
\hline $\begin{array}{l}\text { Definir o tema a ser trabalhado, enfatizando } \\
\text { conteúdos considerados mais relevantes }\end{array}$ & $\begin{array}{l}\text { Escolher novos conteúdos, além daqueles } \\
\text { propostos originalmente }\end{array}$ \\
\hline Definir as metas globais de aprendizagem & $\begin{array}{l}\text { Participar da definição das metas parciais } \\
\text { associadas ao processo de aprendizagem }\end{array}$ \\
\hline Propor estratégias de aprendizagem & Propor estratégias de aprendizagem \\
\hline $\begin{array}{l}\text { Definir os critérios de desempenho, esperados } \\
\text { para o produto final do processo de } \\
\text { aprendizagem }\end{array}$ & $\begin{array}{l}\text { Propor a forma final para o produto, fruto da } \\
\text { aprendizagem desenvolvida }\end{array}$ \\
\hline Definir os prazos globais do processo & Definir prazos parciais das etapas do processo \\
\hline Definir os critérios de avaliação & $\begin{array}{l}\text { Contribuir com propostas a respeito da forma e } \\
\text { do processo de avaliação }\end{array}$ \\
\hline
\end{tabular}




\begin{tabular}{|c|c|}
\hline Professor & Aluno \\
\hline $\begin{array}{l}\text { Prover infraestrutura e recursos para o processo } \\
\text { de ensino e aprendizagem }\end{array}$ & $\begin{array}{l}\text { Complementar a infraestrutura e os recursos } \\
\text { do processo, conforme seu interesse e } \\
\text { disponibilidade }\end{array}$ \\
\hline $\begin{array}{l}\text { Atuar como facilitador, mostrando caminhos e } \\
\text { indicando recursos de apoio à aprendizagem }\end{array}$ & Escolher os caminhos e os recursos para aprender \\
\hline $\begin{array}{l}\text { Dar feedback aos alunos quanto às suas atitudes, } \\
\text { habilidades e conhecimentos }\end{array}$ & $\begin{array}{l}\text { Estruturar os grupos de trabalho e escolher seu } \\
\text { papel no grupo }\end{array}$ \\
\hline
\end{tabular}

Como se nota no Quadro I, a proposta das metodologias ativas consiste em distribuir a responsabilidade pela busca por recursos e a organização do processo de aprendizagem entre professor e aluno. Na verdade, a adoção de metodologias ativas faz parte de uma proposta de repensar o processo de ensino onde o professor deixa de ser um provedor de informações, reduzindo aulas expositivas, e passa aos alunos a responsabilidade pela busca detalhada e aprofundada de conhecimentos.

Dessa forma, o papel do professor passa a ser o de um facilitador no processo de aplicação e uso dos conhecimentos trabalhados, dirimindo dúvidas sobre como esta aplicação pode ser feita de uma maneira mais fácil ou mais adequada a cada caso enfrentado pelos alunos. Nessa abordagem, o professor, basicamente, seleciona conteúdos e passa a trazê-los aos alunos de uma forma desafiadora, instigando-os a resolver situações problemáticas, com fundamentação na teoria associada ao tema em estudo (вUCK, 2008).

Quando os alunos não puderem dispor de conteúdo suficiente para a tomada de decisão, é papel do professor apontar esta carência, instigando-os a buscar novas fontes de informações. Por outro lado, se a limitação ocorrer durante o processo de aplicação dos conteúdos na resolução da situação problema, o professor se vale de toda sua experiência para indicar possíveis caminhos. Esta indicação, não é, entretanto, a construção da solução no lugar do aluno, mas sim a oferta de exemplos ou formas possíveis para se conduzir uma determinada situação (BUCK, 2008).

Um dos possíveis caminhos que um professor poderia oferecer seria apresentar casos reais de outras equipes que estiveram em situação semelhante. Poderia explicar como foram resolvidos os problemas naquela 
situação e convidar os alunos a refletir se esta abordagem, apresentada no exemplo, é aplicável à situação em que o grupo se encontra. Assim sendo, o professor passa a ter um papel muito mais ligado ao de um facilitador, além de ser um elemento de inspiração para os alunos no que diz respeito ao valor do conteúdo que está sendo trabalhado (MAZur, 20I5). Passa a ter, portanto, um papel muito mais motivacional, significativamente diferente do antigo papel de "fonte da informação".

Estes preceitos apresentados são comuns à maioria das abordagens relacionadas com as metodologias ativas. Entretanto, cada metodologia propõe formas diferentes para o processo de apresentação da situação problema e obtenção de novas informações para embasar a solução de uma situação em estudo. Em outras palavras, as metodologias ativas têm diferentes formas de desafiar os alunos, estimulá-los a compreender os conceitos propostos, buscar informação e fazer análises críticas dos resultados obtidos.

Neste artigo se trabalha a aplicação de uma metodologia ativa em particular, que é a TBL. Nesta abordagem, cabe ao professor a proposta de um desafio inicial, obviamente ligado ao objetivo de estudo, o qual é seguido por uma etapa de construção do conhecimento. Na metodologia TBL a busca pela informação é, via de regra, prévia aos encontros realizados em sala de aula. O que se faz presencialmente e em grupo é o debate sobre o real significado das leituras e estudos prévios que os alunos realizaram.

Assim sendo, o pressuposto desta abordagem é que haverá uma busca prévia sobre informações relacionadas ao conteúdo a ser trabalhado em uma dada aula. A disponibilização de material de apoio, com informações, também é parcialmente feita pelo professor, mas os alunos têm a liberdade de buscar fontes de informação complementares. Presencialmente, ocorre um debate sobre os conteúdos previamente lidos pelos alunos, o qual tem como meta verificar se estes foram assimilados. Muito mais importante do que a assimilação, também é objetivo dos encontros verificar se os conceitos foram compreendidos. Com este fim, as discussões presenciais consistem em fazer com que os alunos, ao debaterem entre si sobre um conceito, troquem novas perspectivas e entendimentos sobre um conteúdo previamente preparado. 
A sistemática de aprendizagem baseada em times tem em comum, com as outras metodologias ativas, um momento prévio de preparação, realizado pelos alunos com base nos materiais disponibilizados e sugeridos pelo professor. Em uma segunda etapa, provoca debates com base no desafio proposto pelo professor e, em uma etapa final de fechamento, busca-se o consenso do grupo. No momento do debate final, realizado com o auxílio do professor, procura-se garantir que as interpretações dos fundamentos utilizados estão alinhadas com a teoria. O professor auxilia a verificar se as soluções são pertinentes à situação proposta e consistentes com o desafio que o grupo enfrentou.

A seguir são detalhados os processos e etapas de uso do Team-Based Learning (твL), dinâmica que, como descrito, utiliza a aprendizagem baseada em grupos para a construção de novas competências.

\section{TEAM-BASED LEARNING (TBL)}

A metodologia ativa Team-Based Learning (TBL) (aprendizagem baseada em equipes) foi criada por Larry Michaelsen na década de 70, na Universidade de Oklahoma, para uso acadêmico. Somente em 200I a metodologia foi utilizada na área da medicina e o seu uso vem crescendo, principalmente nos cursos da área de saúde (GOPALAN; FOX; GAEBELEIN, 20I3).

Trata-se de uma estratégia de ensino cujo objetivo é "ir além de simplesmente cobrir conteúdos, mas se concentrar em garantir que os alunos tenham a oportunidade de praticar, usando conceitos do curso para resolver problemas" (MICHAELSEN; KNIGHT; FINK, 2002, p. 7, tradução nossa). Os autores ressaltam que times ou equipes são diferentes de grupos, embora ambos consistam em duas ou mais pessoas que interagem em alguma atividade em comum. Times são caracterizados por um elevado nível de compromisso individual para o bem-estar do grupo e um elevado nível de confiança entre os membros. O processo de tornar um grupo de pessoas em uma equipe requer tempo de interação conjunta, recursos (especialmente intelectuais), uma tarefa desafiadora, a qual se torna objetivo comum, e comentários frequentes sobre o desempenho individual e de grupo. Os autores ainda sugerem que as equipes devem ser compostas de cinco a sete 
integrantes. Como estratégia de ensino, a TBL se compõe em três fases: preparação, aplicação e avaliação. Cada uma destas fases está detalhada no Quadro 2.

Quadro 2 Fases da metodologia Team-Based Learning

\begin{tabular}{|llll|}
\hline Preparação & Aplicação & Avaliação \\
\hline Pré-classe & $\begin{array}{l}\text { Garantia de } \\
\text { preparo - na classe }\end{array}$ & Na classe & Na classe \\
\hline Estudo individual & Teste individual & Debates das equipes & $\begin{array}{l}\text { Provas ou outros testes } \\
\text { individual ou em } \\
\text { grupo }\end{array}$ \\
\hline $\begin{array}{l}\text { Consulta a materiais } \\
\text { como vídeos, } \\
\text { entrevistas, artigos. }\end{array}$ & Teste em equipe & $\begin{array}{l}\text { Testes } \\
\text { (de múltipla escolha, } \\
\text { verdadeiro ou falso) }\end{array}$ & \\
\hline & Apelação & $\begin{array}{l}\text { Resolução de dúvidas } \\
\text { pelo professor }\end{array}$ & \\
\hline & Feedback do professor & & \\
\hline
\end{tabular}

Fonte: Michaelsen, Knight e Fink (2002).

Na primeira fase há a preparação dos estudantes por meio de leituras sobre o tema proposto pelo professor, sendo esta realizada fora da sala de aula. $\mathrm{O}$ professor seleciona os materiais que julgar pertinentes ao tema, podendo ser, por exemplo, um artigo científico, uma reportagem jornalística, uma entrevista, um capítulo de livro ou um vídeo. O objetivo dessa fase é que o aluno tenha um entendimento geral e conceitos básicos o assunto, uma vez que a profundidade virá mais tarde (MICHAELSEN; KNIGHT; FINK, 2002; SIMONSON, 20I4).

Também integra essa etapa um conjunto de atividades que visa verificar o grau de preparo pré-classe por parte dos alunos. Neste ponto, os estudantes recebem questões sobre o tema, frequentemente no formato de múltipla escolha, respondendo-as individualmente. Isto caracteriza a "garantia de preparo individual", sendo que a pontuação resultante tem um peso prédefinido (geralmente de $30 \%$ ) da avaliação global.

Logo após o preenchimento e entrega ao professor das respostas individuais, as mesmas questões são discutidas na equipe, havendo o debate sobre eventuais divergências em relações às respostas individuais. Dos 
debates deve surgir uma nova proposta de respostas, fruto do consenso, as quais buscam caracterizar a "garantia de preparo do grupo". Estas respostas têm um peso maior na avaliação global $(70 \%)$. O ideal é que a equipe seja construída de forma aleatória, buscando uma diversidade de níveis de conhecimento e de experiências e, se possível, sem vínculos de amizade.

Após a correção das respostas, um grupo poderá fazer uma "apelação" ao professor, apresentando, na forma escrita, uma pequena defesa do seu ponto de vista e de como interpretou uma questão, fundamentando a escolha por uma determinada resposta. Havendo fundamento na apelação, o professor poderá dar os pontos correspondentes à questão revista. Finalmente, baseando-se nos resultados das avaliações individuais e em grupo, o professor parte para resolução de dúvidas sobre os conceitos e eventuais lacunas de conhecimento que possam ter sido identificadas. O professor também pode apresentar comentários adicionais e trazer exemplos que julgar pertinentes para o entendimento correto dos conceitos-chave (MICHAELSEN; KNIGHT; FINK, 2002; SIMONSON, 20I4).

A segunda fase é a de aplicação dos conceitos estudados. Neste momento, os alunos irão utilizar a base teórica estudada, enfrentando desafios que somente poderão ser resolvidos com o uso desta. Assim como na etapa de preparação, também a etapa de aplicação pode ser realizada propondo-se questões a respeito de um problema ou solicitando-se uma interpretação cuja solução será avaliada de duas formas: no pequeno e no grande grupo. Agora, os debates na equipe consistem na primeira fase da avaliação e os debates no grande grupo na fase final. Assim, os estudantes podem discutir um problema e obter consenso em sua equipe e, ao mesmo tempo, ter novas perspectivas sobre a mesma situação, oriundas das discussões de outros grupos (MICHAELSEN; KNIGHT; FINK, 2002; SIMONSON, 20I4).

De forma semelhante ao que ocorre no final da etapa de preparação, também a de aplicação se encerra com a participação do professor de maneira mais ativa. Após os debates no grande grupo, cabe ao professor a resolução de dúvidas que ainda tenham restado em relação aos pontos trabalhados, o esclarecimento sobre eventuais inconsistências nos resultados encontrados, as complementações com casos particulares ou outros exemplos de aplicação do conhecimento em pauta. 
O processo como um todo se conclui com a etapa de avaliação. Não há variantes significativas dessa etapa, quando comparada com os métodos tradicionais, uma vez que é composta por provas ou outros testes, os quais poderão ser individuais ou em grupo. Uma pequena variante, entretanto, é que a avaliação também pode incluir uma análise da aplicação do TBL como método de aprendizagem, solicitando-se ao aluno um posicionamento crítico. Um dos ganhos esperados dessa proposta é o de que o aluno possa rever seu papel ao longo do método, refletindo sobre atitudes ou posturas que contribuíram ou prejudicaram sua aprendizagem. Como resultado, se espera que essa reflexão gere mudanças de comportamento que poderão beneficiar o aluno em edições futuras da aplicação do método.

De acordo com os autores, a metodologia TBL proporciona uma maior parceria aluno-aluno e aluno-professor, maior interação, motivação, energia e entusiasmo em sala de aula, diferentemente do que ocorre em uma aula tradicional. Como visto quando da apresentação dos fundamentos das metodologias ativas, no TBL o aluno tem o papel mais importante na sala de aula, com muito mais envolvimento na aprendizagem, permitindo ao professor, mesmo que em um papel mais secundário, melhor observar, ouvir e refletir sobre o processo de ensino.

Essa metodologia possui alguns desafios para a sua implantação como, por exemplo, o de que é necessário a aula com base nas etapas do TBL, levando em consideração os objetivos de aprendizagem. Além disso, o aluno precisa realmente cumprir essas etapas, começando com a sua preparação individual, uma vez que a falta desta compromete o desempenho da sua equipe. O professor, por sua vez, necessita verificar esse preparo, ou seja, ter uma garantia de preparo do aluno por meio de um teste, que houve a reflexão inicial por parte do aluno. Outro desafio importante é que a implantação do TBL requer quatro princípios fundamentais: equipes heterogêneas (de cinco a sete integrantes), mantidas ao longo das atividades, responsabilidade do aluno por seu trabalho individual e em grupo, atividades que promovam a aprendizagem e o crescimento da equipe e oferta constante de feedback por parte do professor (MICHAELSEN; KNIGHT; FINK, 2002). 


\section{TRABALHO DE CONCLUSÃO DE CURSO (TCC)}

O Trabalho de Conclusão de Curso (TCC), criado em 1983, se caracteriza no Brasil como "um tipo de trabalho acadêmico amplamente utilizado no ensino superior como forma de efetuar uma avaliação final dos graduandos e que contemple a diversidade dos aspectos de sua formação universitária” (NEHER, 2009, p. 2). De acordo com a proposta da Associação Brasileira de Normas Técnicas (ABNT, 2002), o trabalho de conclusão de curso deve seguir uma normativa padrão que consiste em elementos pré-textuais, textuais e pós-textual. Os elementos pré-textuais obrigatórios são a capa, a folha de rosto, a folha de aprovação, o resumo na língua vernácula e na língua estrangeira e o sumário. Os elementos textuais são compostos por introdução, desenvolvimento e conclusão, seguidos do elemento pós-textual obrigatório que são as referências. Com base no que propõe Ferreira Júnior (20II), os elementos textuais são mais bem detalhados caso se considere como seus componentes a introdução, a formulação do problema de pesquisa, os objetivos, a justificativa, o referencial teórico, a estratégia metodológica, a apresentação e análise dos resultados e as considerações finais.

Apesar dessas recomendações, os tipos de TCC variam, de acordo com cada instituição de ensino. Eles podem ser solicitados na forma de um estudo de caso, de uma revisão bibliográfica ou de uma pesquisa de campo, entre outros (NEHER, 2009). Por exemplo, na instituição dos autores desse artigo, o aluno do curso de Publicidade e Propaganda deve realizar um plano monográfico, enquanto que o aluno do curso de Administração de Empresas pode optar por desenvolver um plano monográfico, um plano de negócio ou um plano estratégico (INSTITUIÇão DOS AUTORES, 20I4).

O TCC monográfico reúne as características tradicionais desse tipo de estudo, versando sobre temas considerados relevantes à Administração ou à Comunicação Social. Este parte de uma questão de pesquisa, formulada com o suporte de referenciais teóricos e documentais, a qual resulta em uma pesquisa de campo. Espera-se que os achados da pesquisa sejam capazes de fundamentar descrições, interpretações, análises e demonstrações, cuja elaboração reflita a capacidade do estudante de utilizar o que aprendeu no curso para compreender novas situações (INSTITUIÇão DOS AUTORES, 20I4). 
Para o TCC monográfico a construção de um referencial teórico consistente é indispensável, na medida em que permite aos estudantes fundamentar tais descrições, interpretações, análises e demonstrações. A realização do trabalho deve representar uma contribuição de natureza descritivo-analítica relevante à área explorada pela pesquisa e a base teórica determinará o alcance possível para um trabalho reflexivo fundamentado.

O TCC na modalidade de Plano de Negócio (PN) contempla as questões típicas de estudos de viabilidade econômico-financeira de um novo empreendimento. Uma pequena variante é representada pela modalidade de TCC do tipo Plano Estratégico (PE), onde a análise de viabilidade se dirige às diretrizes e iniciativas de ordem estratégica e tática de um negócio existente (INSTITUIÇÃO DOS AUTORES, 20I4).

No TCC plano de negócios a situação concreta configura-se a partir da seleção de um empreendimento, percebido como oportunidade de negócio, buscando-se analisar sua viabilidade para efetiva implantação. Caracterizase, portanto, como a concepção de um negócio em que uma nova empresa apresenta-se como entrante no ramo escolhido (CECCONELLO; AZJENTAL, 2008). No Tcc plano estratégico, a situação concreta se configura na análise das opções competitivas que uma empresa real, já em operação, poderá adotar no futuro. O resultado é uma concepção estratégica, desdobrada nos níveis táticos e operacionais, com a avaliação dos retornos esperados quando da implantação do plano (BORN, 2009).

Como se pode notar, estes dois tipos de TCcs são trabalhos de aplicação de conceitos e modelos teóricos em uma situação concreta, uma vez que não buscam discutir o mérito de qualquer proposição teórica. Trata-se, portanto, de aplicação fundamentada, a qual demanda a justificação da escolha da base teórica do trabalho, indicando a forma e as condições em que são utilizadas. Em ambos os casos, o objetivo do trabalho é analisar a organização sob o ponto de vista da geração, do atendimento e da manutenção da demanda, envolvendo os aspectos técnicos, financeiros e econômicos, levando à apreciação qualitativa e quantitativa de sua viabilidade e sustentabilidade (CECCONELLO; AZJENTAL, 2008).

É importante destacar que todos os três tipos de Tccs compartilham os seguintes elementos em comum: introdução, formulação do problema de 
pesquisa, objetivos, justificativa, referencial teórico, estratégia metodológica, apresentação e análise dos resultados e considerações finais. Como já mencionado, a maior distinção se encontra no referencial teórico, o qual é mais extenso e aprofundado nos tccs monográficos, sendo menor nos casos dos planos. Além disso, outra diferença relevante se dá na análise dos resultados.

Nos tccs monográficos a análise dos resultados se caracteriza pela construção de hipóteses, proposição de modelos, reflexões e formalização de relações que precisam estar fortemente ligadas às teorias vigentes, apresentadas no referencial teórico. Nos tccs de planos de negócio e estratégico, a análise dos resultados se traduz por análises de mercado e de ambiente, seguidas pela proposição dos planos propriamente ditos. Devem se constituir, portanto, em propostas consistentes para estruturação de um negócio ou de uma estratégia.

Esta similaridade nas estruturas dos três Tccs permitiu que a metodologia TBL fosse aplicada em diferentes etapas de construção do trabalho e, também, nos dois cursos de graduação. Nesta pesquisa, o TBL foi utilizado no curso de Publicidade e Propaganda nas etapas de formulação do problema e de elaboração da estratégia metodológica e no curso de Administração na etapa de análise dos resultados (proposição) dos planos de negócio e estratégico.

$\mathrm{Na}$ instituição dos autores desse artigo a realização dessas etapas ocorre em disciplinas com nomes distintos, porém com o mesmo objetivo de instrumentalizar os alunos nas etapas iniciais de definição do trabalho. Como essa etapa inicial se desenvolve em grupo, ou seja, como uma disciplina regular e não individual, foi oportuno utilizar о твL como metodologia de ensino e aprendizagem. A forma como a metodologia ativa foi aplicada, bem como a estratégia de pesquisa empregada, está detalhada no próximo a seguir. 


\section{ESTRATÉGIA METODOLÓGICA}

A estratégia metodológica adotada nesse artigo contou com uma pesquisa primeiramente de vertente qualitativa, a qual, segundo Malhotra (200I), se preocupa com a profundidade do contexto pesquisado, tem ênfase na subjetividade e trabalha com dados não mensuráveis. Nesse sentido, utilizouse a vertente qualitativa para compreender o comportamento dos pesquisados em relação à metodologia aplicada utilizando-se da técnica de observação. Essas observações, realizadas pelos professores das disciplinas, serviram de base para identificação dos fatores que iriam compor o instrumento de coleta de dados, os quais foram avaliados na segunda etapa da pesquisa.

Na segunda etapa empregou-se a vertente quantitativa que, segundo Mattar (200I), tem ênfase na objetividade e os resultados são quantificados. Adotouse uma pesquisa conclusiva para avaliar a percepção dos alunos a respeito da metodologia ativa TBL na construção do Trabalho de Conclusão de Curso (TCC).

As técnicas de coleta de dados exploradas foram, além da observação não participante, a pesquisa bibliográfica e os questionários. Segundo Stumpf (2005), a pesquisa bibliográfica serve para a revisão da literatura, isto é, para a construção do referencial teórico. Nesse trabalho, utilizou-se a pesquisa bibliográfica por meio de livros e artigos científicos. Marconi e Lakatos (2008) propõem que a observação participante consiste na participação real do pesquisador, com o objetivo de "ganhar a confiança do grupo, fazer os indivíduos compreender a importância da investigação, sem ocultar o seu objetivo ou sua missão [...]" (MARCONI; LAKATOS, 2008, p. 79). Conforme mencionado, coube aos professores a realização dessa etapa, sendo que estes apresentaram a proposta do trabalho aos alunos, interagiram com o grupo pesquisado e utilizaram de anotações das impressões do campo.

O questionário "é um instrumento de coleta de dados constituído por uma série ordenada de perguntas, que devem ser respondidas por escrito e sem a presença do entrevistador" (MARCONI; LAKATOS, 2008, p. 86). Nesta pesquisa o questionário foi composto por 12 questões, cuja resposta consistia em assinalar uma das opções em uma escala Likert, com cinco categorias. O questionário adotado (vide Anexo I) também contempla as orientações que foram dadas 
aos alunos quanto ao objetivo da pesquisa e à sua forma de preenchimento, explicando, por exemplo, que a escala variava de i a 5 , sendo " $\mathrm{I}$ " associado a "discordo totalmente" e " 5 " a "concordo totalmente". A aplicação da pesquisa ocorreu ao final do último dia de uso da metodologia TBL.

A amostra foi composta pelo total de 49 alunos, sendo 27 deles pertencentes ao curso de Publicidade e Propaganda (PP) e 22 ao curso de Administração de Empresas (ADM). A Tabela I detalha as unidades de estudo.

Tabela I Caracterização dos entrevistados

\begin{tabular}{|c|c|c|c|c|c|c|}
\hline Disciplina & Curso & $\begin{array}{l}\text { Semestre } \\
\text { do curso }\end{array}$ & $\begin{array}{l}\text { Número de } \\
\text { alunos na } \\
\text { disciplina }\end{array}$ & $\begin{array}{l}\text { Datas da } \\
\text { aplicação } \\
\text { do método } \\
\text { TBL }\end{array}$ & $\begin{array}{l}\text { Conteúdo } \\
\text { discutido }\end{array}$ & $\begin{array}{l}\text { Número } \\
\text { de alunos } \\
\text { pesquisados }\end{array}$ \\
\hline \multirow[t]{2}{*}{ Pesquisa III } & \multirow{2}{*}{$\begin{array}{l}\text { Publicidade e } \\
\text { Propaganda }\end{array}$} & \multirow{2}{*}{$\begin{array}{l}8^{\circ} \\
\text { semestre }\end{array}$} & \multirow[t]{2}{*}{27} & $\begin{array}{l}17 \text { de março } \\
\text { de } 2015\end{array}$ & $\begin{array}{l}\text { Formulação do } \\
\text { problema de } \\
\text { pesquisa de uma } \\
\text { Monografia }\end{array}$ & 26 \\
\hline & & & & $\begin{array}{l}31 \text { de março } \\
\text { de } 2015\end{array}$ & $\begin{array}{l}\text { Estratégia } \\
\text { metodológica de } \\
\text { uma Monografia }\end{array}$ & 23 \\
\hline \multirow{2}{*}{ TCC I } & \multirow{2}{*}{$\begin{array}{l}\text { Administração } \\
\text { de Empresas }\end{array}$} & \multirow{2}{*}{$\begin{array}{l}90 \\
\text { semestre }\end{array}$} & \multirow{2}{*}{22} & \multirow{2}{*}{$\begin{array}{l}\text { Ao longo } \\
\text { de todo o } \\
\text { semestre de } \\
2014 / 2\end{array}$} & $\begin{array}{l}\text { Componentes } \\
\text { de um Plano de } \\
\text { Negócios }\end{array}$ & 11 \\
\hline & & & & & $\begin{array}{l}\text { Componentes } \\
\text { de um Plano } \\
\text { Estratégico }\end{array}$ & 7 \\
\hline
\end{tabular}

É válido destacar que a disciplina de Pesquisa III do curso de Publicidade e Propaganda equivale à disciplina de Estratégia Metodológica para o TCC do curso de Administração de Empresas, sendo seu foco principal a elaboração individual do projeto de pesquisa. Já a disciplina de TCC I do curso de Administração desenvolve ainda mais o projeto de pesquisa, aplicando os conceitos trabalhados e iniciando a construção de um Plano de Negócios ou um Plano Estratégico. Em ambos os casos (PP e ADM), a última etapa do trabalho de conclusão de curso é a disciplina de TCC II, mais focada na parte empírica e de análise dos dados, bem como das análises de viabilidade dos planos. 
A análise dos dados qualitativos, oriundos das observações dos professores, foi feita por meio de uma categorização simples, agrupando comportamentos e manifestações dos alunos em temas definidos a posteriori. Esses temas formaram a base para a elaboração do questionário. Para a análise dos dados quantitativos utilizou-se a técnica de análise estatística por meio do software Minitab, versão I7.I. De acordo com Oppenheim (I992 apud ROESCH, I996, p. I42) na análise estatística se pode "calcular médias, computar percentagens, examinar os dados para verificar se possuem significância estatística, podemse calcular correlações, ou tentar várias formas de análise multivariada”. Para esse estudo foram desenvolvidos sumários estatísticos, com cálculo de margem de erro, seguidos de análise de conglomerados (clusters). A análise de conglomerados visa identificar grupos de elementos com um perfil o mais semelhante possível, com base nas variáveis escolhidas para caracterizálos. Além disso, é necessário definir quais os critérios que se utilizará para medir as distinções entre os grupos. O primeiro deles é a forma como a diferença de valores entre as variáveis será medida. Neste estudo adotamos a chamada medida "Euclidiana» que é a distância linear entre dois pontos, com base em suas coordenadas. Outro aspecto a ser definido é o chamado "método de ligação" que trata do critério para se definir o que é um grupo mais ou menos homogêneo. Optou-se pelo método de "Ward", o qual tem como característica procurar montar grupos com a menor variabilidade entre os seus componentes. Em outras palavras, o método de Ward prioriza a montagem de grupos em que seus integrantes são o mais parecidos entre si. Como forma de sintetizar essas propostas, se obtém um gráfico (dendograma) o qual apresenta como cada elemento do conjunto de dados foi se ligando aos outros, até a formação dos agrupamentos finais (clusters). Após a análise do dendograma inicial, sem agrupamentos pré-definidos, foram escolhidos três níveis para descrever o conjunto de dados, sendo refeita a análise com esta escolha. Por fim, por meio da comparação das médias das questões de cada subgrupo com a média global, foram identificados os comportamentos com diferença significativa, tabulando-os e analisando o perfil resultante. 


\section{APLICAÇÃO DA METODOLOGIA ATIVA TEAM-BASED LEARNING (TBL)}

O processo para a aplicação da metodologia ativa Team-Based Learning (TBL) nos dois cursos apresentados foi feito de maneira semelhante, porém com frequência de uso distinta. Em ambos os cursos a aplicação consistiu em cinco etapas, conforme apresentado na Figura 2.

Figura 2 Processo de aplicação da metodologia ativa Team-Based Learning (TBL)

Preparação

Para a disciplina de Pesquisa III, o professor explicou o funcionamento da metodologia TBL na etapa de "preparação", tendo disponibilizado materiais e referências bibliográficas por meio da plataforma Blackboard Learn ${ }^{\mathrm{I}}$, para preparação da atividade. No início da aula seguinte (início da aplicação), o professor pediu para que a turma se organizasse em grupos de, no máximo, cinco alunos. Logo após, entregou uma folha contendo questões para os alunos discutirem. A aplicação foi de 45 minutos e, ao final desse tempo, os alunos entregaram o exercício valendo 0,5 pontos.

O fechamento do trabalho foi realizado pelo professor depois que todos entregaram o exercício. Alguns alunos trouxeram dúvidas dos seus grupos e o professor debateu com o grande grupo durante cerca de 15 minutos. Na etapa "pós-aula", o professor corrigiu as respostas dos alunos e postou as notas e um arquivo com as rubricas de respostas e pontuação no Blackboard Learn. Na última aula da disciplina foi entregue o questionário para a avaliação da metodologia TBL.

Na disciplina de TCCI, do curso de Administração de Empresas, a aplicação teve uma abordagem um pouco diferente, tendo em vista que os alunos

\footnotetext{
1 A plataforma Blackboard Learn é um Ambiente Virtual de Aprendizagem (AVA) que serve de interface tecnológica entre professor e aluno.
} 
já haviam cursado a disciplina de Estratégia Metodológica para o TCC e que todos os conceitos tinham sido trabalhados previamente. Assim, essa disciplina antecedente foi considerada como a etapa de preparação, sendo que, no início da aplicação do TBL, além de ser explicada a técnica para os alunos, foi estabelecido um compromisso de que todos deveriam trazer seu projeto de pesquisa como fonte principal de consulta.

Baseado no histórico de dúvidas que os alunos apresentavam em edições anteriores da disciplina, o professor desenvolveu um conjunto de questões que trabalhavam os aspectos de maior dificuldade. Assim sendo, em cada aula, um grupo de conceitos era trabalhado, sendo que as questões solicitavam sua aplicação nos planos de negócio ou estratégico para o empreendimento ou empresa real escolhida pelo aluno.

Na etapa de aplicação, em grupos de quatro a seis alunos, se discutiam os conceitos propostos, anotando-se os pontos fundamentais. O professor somente intervinha nessa etapa se a tarefa não tivesse ficado clara. Neste momento, o grupo formalizava suas conclusões em um documento. $\mathrm{Na}$ sequência, capitaneados por um apresentador, todos debatiam o tema simultaneamente (não havia apresentações por grupo). Todos apresentavam suas conclusões ao grande grupo, discutindo-se até que se obtivesse consenso. Nesse momento (fechamento), o facilitador auxiliava o grupo, esclarecendo conceitos e guiando o debate para a resolução de eventuais divergências.

Com os pontos fundamentais propostos e condensados, cada aluno, individualmente, redigia um esboço de como esses seriam trabalhados no seu plano. Após os debates e o fechamento, ainda foi disponibilizado tempo para orientações individuais. Ao longo do semestre letivo foram estabelecidos três momentos de entrega para as propostas dos alunos (planos parciais). Na aula seguinte a cada uma das entregas, o professor deu um feedback individual, relatando destaques positivos e apontando oportunidades de melhoria nos planos. 


\section{APRESENTAÇÃO E ANÁLISE DOS RESULTADOS}

Nesta seção se apresentam os resultados dos ensaios realizados com as duas turmas pesquisadas. Para cada um dos dois casos de aplicação, se inicia a apresentação dos resultados com as anotações do professor, realizadas durante o processo de observação participante. Fotos ilustrativas da aplicação do TBL estão dispostas ao final desse relato inicial. Na sequência, se apresentam os indicadores relacionados aos questionários aplicados. Um quadro síntese, com as médias e a margem de erro das pontuações dadas pelos alunos em cada questão, destaca os aspectos da aplicação da metodologia que foram considerados com maior unanimidade. Logo a seguir, apresenta-se o descritivo da análise de clusters (três), bem como um quadro com a tabulação das respostas características de cada grupo.

\section{RESULTADOS DA APLICAÇÃO DO TBL NA DISCIPLINA DE PESQUISA III} A aplicação da metodologia tBL na disciplina de Pesquisa III (curso de Publicidade e Propaganda) ocorreu de maneira pontual, em duas aulas. Apresentam-se, inicialmente, os resultados da observação participante, sintetizados com base nas impressões do professor da disciplina e de verbalizações dos alunos.

Com base no professor, o clima percebido inicialmente era de tensão, pois até o momento os alunos não tinham vivenciado essa metodologia. As expressões iniciais dos alunos foram "isso é muito difícil", "ainda bem que não isso não será em todas as aulas" e "poxa, qual será que é a droga dessa resposta?», evidenciando certa reprovação da metodologia. Mas, durante as discussões, o clima tenso foi dando lugar a uma descontração com seriedade e a um entendimento melhor da proposta da metodologia, com expressões como "até que isso é legal" e "estou gostando de fazer esse trabalho". Entretanto, ainda havia quem estivesse inseguro com a metodologia e não confiando muito nos resultados da discussão com o seu grupo: "professor, você pode nos explicar depois?”. Nessa linha, alguns alunos chamavam o professor para que ele explicasse uma dúvida do grupo, mas o professor reforçava que não era esse o objetivo e que, posteriormente debateriam sobre as dúvidas que ainda restassem, evidenciando as fases da metodologia TBL. 
Na primeira aplicação (conteúdo sobre formulação do problema de pesquisa) o professor percebeu que muitos alunos chegaram atrasados à aula, embora tivesse reforçado, na aula anterior, sobre a importância da pontualidade. Alguns não participaram do debate (e foram alertados pelo professor) e poucos estavam realmente preparados para o exercício (com resumo dos livros sugeridos ou textos grifados, evidenciando a leitura). Poucos alunos tomavam nota do que estava sendo discutido. Porém, na segunda aplicação (sobre estratégia metodológica), a mudança foi drástica: a maioria dos alunos estava pontualmente na sala de aula; praticamente todos os alunos participaram do debate e a maioria estava com o material impresso da aula, com as devidas anotações. Alguns possuíam livros que tinham sido sugeridos pelo professor na aula anterior, sem contar que vários deles estavam tomando nota da discussão, mostrando maior interação e motivação, conforme propõe a abordagem TBL. O professor acredita que isso se justifique por dois motivos: o desempenho abaixo da média na primeira aplicação - valia meio ponto e a maioria tirou o,I - e, também, por conseguirem entender melhor o objetivo da metodologia.

A Figura 3 mostra a aplicação do TBL na turma de Pesquisa III. A imagem da esquerda apresenta uma aluna desenvolvendo a resposta com atenção e outra, à sua frente, com um livro aberto durante o debate no pequeno grupo. $\mathrm{Na}$ imagem da direita, vários grupos estão discutindo sobre seus achados e alguns, com auxílio de computador, tomam notas antes da discussão no grande grupo.

Figura 3 Aplicação da metodologia TBL na turma de Pesquisa III

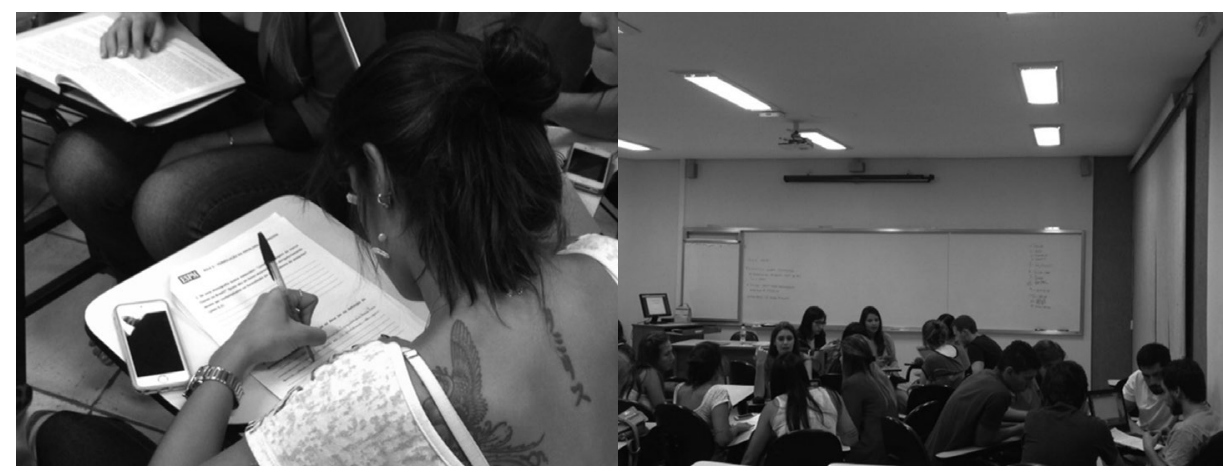


Após o último dia de experimentação da metodologia ativa, aplicou-se o questionário (vide Anexo I) para que os alunos refletissem sobre a experiência e apontassem as suas opiniões. Com base nos resultados, apresenta-se a Tabela 2, contendo o resumo das médias, a mediana e as margens de erro das respostas, com $95 \%$ de confiança.

Tabela 2 Estatística descritiva das respostas dos alunos de Pesquisa III

\begin{tabular}{|lllllllllllll|}
\hline Variável & $\mathbf{Q 1}$ & $\mathbf{Q 2}$ & $\mathbf{Q 3}$ & $\mathbf{Q 4}$ & $\mathbf{Q 5}$ & $\mathbf{Q 6}$ & $\mathbf{Q 7}$ & $\mathbf{Q 8}$ & $\mathbf{Q 9}$ & $\mathbf{Q 1 0}$ & $\mathbf{Q 1 1}$ & Q12 \\
\hline Média & $\mathbf{3 , 2 6}$ & $\mathbf{3 , 1 7}$ & 2,43 & 2,43 & 2,52 & 2,74 & $\mathbf{1 , 3 5}$ & $\mathbf{2 , 0 0}$ & $\mathbf{1 , 4 3}$ & $\mathbf{1 , 7 8}$ & 2,22 & 2,65 \\
\hline Mediana & 3,00 & 3,00 & 3,00 & 2,00 & 2,00 & 3,00 & 1,00 & 2,00 & 1,00 & 2,00 & 2,00 & 2,00 \\
\hline Margem de erro (95\%) & 0,59 & $\mathbf{0 , 5 5}$ & $\mathbf{0 , 4 7}$ & $\mathbf{0 , 6 4}$ & $\mathbf{0 , 5 8}$ & $\mathbf{0 , 5 6}$ & $\mathbf{0 , 3 8}$ & $\mathbf{0 , 2 9}$ & $\mathbf{0 , 3 7}$ & $\mathbf{0 , 3 7}$ & $\mathbf{0 , 5 4}$ & $\mathbf{0}, 58$ \\
\hline
\end{tabular}

$\mathrm{Na}$ Tabela 2 foram destacadas as maiores e as menores médias do conjunto de entrevistas realizadas. Com base nos valores apontados, percebe-se que a maioria dos alunos disse preferir um feedback do professor do que do colega (Q9), o que é consistente com o resultado da questão 7 (Q7), por meio da qual disseram que o fechamento feito pelo professor não pode ser dispensado, bem como com da questão I (QI), em que a orientação do professor é preferida em relação ao debate com o grupo. Por outro lado, a maioria dos alunos disse que a discussão no grupo permitiu ter consciência sobre o quanto realmente sabia sobre o assunto trabalhado (Q2) e que os debates nos pequenos grupos são suficientes para garantir a aprendizagem sobre o tema em questão, não sendo necessário discuti-los no grande grupo (Qıo).

Uma análise de médias globais, embora útil para determinar percepções gerais, pode ser detalhada ao se proceder à análise de clusters. O objetivo da análise de cluster é verificar se existem subgrupos de indivíduos com comportamento semelhante, explicando melhor a diversidade de opiniões e hábitos de um grupo maior. Nesse sentido, a Tabela 3 apresenta o resultado da análise de clusters para a turma de Pesquisa III, apresentando, além da média global, as médias por questão em cada subgrupo identificado. 
Tabela 3 Média global e por subgrupo, oriundas da análise de cluster na turma de Pesquisa III

\begin{tabular}{|lllll|}
\hline Variável & Cluster 1 & Cluster $\mathbf{2}$ & Cluster 3 & Média Geral \\
\hline Q1 & $\mathbf{4 , 8}$ & 1,8 & $\mathbf{3 , 6}$ & 3,3 \\
\hline Q2 & 3,3 & $\mathbf{3 , 4}$ & 2,9 & 3,2 \\
\hline Q3 & 2,3 & $\mathbf{2 , 6}$ & 2,3 & 2,4 \\
\hline Q4 & $\mathbf{4 , 5}$ & 1,8 & $\mathbf{1 , 7}$ & 2,4 \\
\hline Q5 & $\mathbf{3 , 0}$ & 2,6 & $\mathbf{2 , 1}$ & 2,5 \\
\hline Q6 & $\mathbf{2 , 0}$ & $\mathbf{4 , 0}$ & 2,1 & 2,7 \\
\hline Q7 & $\mathbf{1 , 7}$ & 1,3 & $\mathbf{1 , 2}$ & 1,3 \\
\hline Q8 & $\mathbf{1 , 7}$ & $\mathbf{2 , 4}$ & 1,9 & 2,0 \\
\hline Q9 & 1,3 & 1,3 & $\mathbf{1 , 7}$ & 1,4 \\
\hline Q10 & $\mathbf{1 , 5}$ & $\mathbf{2 , 1}$ & 1,7 & 1,8 \\
\hline Q11 & $\mathbf{3 , 2}$ & 1,9 & 1,9 & 2,2 \\
\hline Q12 & $\mathbf{2 , 2}$ & $\mathbf{4 , 0}$ & $\mathbf{1 , 8}$ & 2,7 \\
\hline
\end{tabular}

A fim de mais facilmente se identificar as características de cada cluster, foram grifadas com fundo cinza claro e números em preto as médias de subgrupo com valores acima da média global. Da mesma forma, foram grifadas com fundo escuro e números em branco as médias de subgrupo que estavam abaixo da média global.

Nota-se que todas as variáveis contribuíram para distinção do comportamento dos subgrupos (clusters). Com o intuito de facilitar a interpretação dos resultados e melhor caracterizar cada subgrupo, foi construído o Quadro 3, registrando-se somente as opiniões significativamente divergentes da média global. 
Quadro 3 Descrição do perfil de cada subgrupo com base no questionário para a turma de Pesquisa III

\begin{tabular}{|c|c|c|}
\hline Perfil do Cluster 1 & Perfil do Cluster 2 & Perfil do Cluster 3 \\
\hline $\begin{array}{l}\text { Prefere orientação individual a } \\
\text { debater com o grupo }\end{array}$ & $\begin{array}{l}\text { Considera que discussão } \\
\text { no grupo permitiu tomar } \\
\text { consciência sobre o quê sabia } \\
\text { de fato }\end{array}$ & $\begin{array}{l}\text { Prefere orientação individual a } \\
\text { debater com o grupo }\end{array}$ \\
\hline $\begin{array}{l}\text { Acredita que aprenderia mais } \\
\text { se fosse necessário entregar ao } \\
\text { professor um pequeno relatório } \\
\text { sobre o assunto debatido no } \\
\text { grupo }\end{array}$ & $\begin{array}{l}\text { Considera que os estudos prévios } \\
\text { que fez são suficientes para o } \\
\text { debate }\end{array}$ & $\begin{array}{l}\text { Não considera que a discussão } \\
\text { no grupo permitiu tomar } \\
\text { consciência sobre o quê sabia } \\
\text { de fato }\end{array}$ \\
\hline $\begin{array}{l}\text { Gostaria de redigir o capítulo } \\
\text { do projeto imediatamente após } \\
\text { a discussão com o grupo }\end{array}$ & $\begin{array}{l}\text { Acredita ter aprendido muito } \\
\text { com os colegas }\end{array}$ & $\begin{array}{l}\text { Prefere não ter que entregar ao } \\
\text { professor um relatório sobre o } \\
\text { debate }\end{array}$ \\
\hline $\begin{array}{l}\text { Não acredita ter aprendido com } \\
\text { os colegas no debate em grupo }\end{array}$ & $\begin{array}{l}\text { Acredita que em grupo aprende } \\
\text { mais do que com o professor }\end{array}$ & $\begin{array}{l}\text { Não quer redigir o capítulo do } \\
\text { projeto imediatamente após a } \\
\text { discussão com o grupo }\end{array}$ \\
\hline \multirow[t]{2}{*}{$\begin{array}{l}\text { Acredita que aprenderia mais se } \\
\text { tivesse que entregar a redação } \\
\text { do item do projeto ao final do } \\
\text { debate }\end{array}$} & $\begin{array}{l}\text { Considera que o debate no } \\
\text { pequeno grupo é suficiente, não } \\
\text { sendo necessário o debate no } \\
\text { grande grupo }\end{array}$ & Não gostou da abordagem TBL \\
\hline & $\begin{array}{l}\text { É o que mais gostou da } \\
\text { abordagem TBL }\end{array}$ & \\
\hline
\end{tabular}

Uma análise do Quadro 3 possibilita inferir a respeito dos estilos de aprendizagem de cada aluno e, portanto, a respeito da forma de interagir com o processo de ensino em cada caso. Ao se considerar as afirmativas relacionadas ao cluster I, percebe-se que estes alunos não valorizaram o conhecimento dos colegas de equipe, preferindo a orientação individual do professor. Entretanto, preferem redigir um relatório sobre o debate e, até mesmo, uma versão inicial do capítulo do projeto para entrega ao professor, sendo mais pragmáticos. Com esse perfil, um nome representativo para esse agrupamento poderia ser o de "Prático", no sentido de preferir desenvolver logo a tarefa.

O perfil do cluster 2 valoriza o conhecimento obtido no pequeno grupo, uma vez que acredita ter aprendido com os colegas, bem como que aprende mais com o grupo do que conversando com o professor. Sentem-se, inclusive, seguros para ensinar algum colega, embora considera a discussão no pequeno grupo suficiente, dispensando a discussão em grandes grupos. 
Consequentemente, foi o grupo que mais gostou da metodologia TBL. Com esse perfil, um nome representativo para esse agrupamento poderia ser o de "Colaborativo", no sentido de apreciar a interação e realizar ações em comum, ou seja, construir o conhecimento em grupo.

Nessa linha de pensamento, nota-se que esse grupo é claramente aberto à metodologia TBL, que tem como pressuposto uma aprendizagem ativa. Esse grupo manifesta todos os aspectos ressaltados por Gopalan, Fox e Gaebelein (2013) quando participantes de uma metodologia ativa efetiva, quais sejam, que o aluno é estimulado a desenvolver, processar, discutir e, como consequência, aumenta sua capacidade intelectual sobre um assunto específico, sempre na forma de uma interação de equipe.

O cluster 3 , por sua vez, apresenta um perfil totalmente oposto ao cluster 2. Esse grupo de alunos prefere uma orientação individual nem entende que a discussão do grupo tenha agregado para o seu conhecimento. Além disso, não deseja redigir o seu projeto logo após a discussão, de modo a ter um melhor aproveitamento e, menos ainda, deseja entregar ao professor um pequeno relatório sobre o assunto debatido no grupo. Consequentemente, foi o grupo que não gostou da abordagem de aprendizagem baseada em times. Um nome representativo para o cluster 3 poderia ser "Tradicional", no sentido de esperar que o professor "ensine" para que ele "aprenda", não se engajando de maneira ativa na aquisição do conhecimento. Teixeira (1985) defende que, de uma forma geral, esse é o sistema educacional brasileiro, ou seja, centrado no professor e não no aluno.

\section{RESULTADOS DA APLICAÇÃO DO TBL NA DISCIPLINA DE TCC I}

A aplicação da metodologia TBL na disciplina de TCC I (curso de Administração) acabou ocorrendo em Ir aulas, sendo que os outros encontros da disciplina foram destinados a avaliações, feedbacks e orientações exclusivamente individuais. Apresentam-se, inicialmente, os resultados da observação participante, sintetizados com base nas impressões do professor da disciplina e de manifestações explícitas dos alunos.

De acordo com o professor, o clima percebido era de muita descontração durante os debates, havendo muita tomada de consciência por parte dos 
alunos. Eram frequentes expressões como "então eu não sei o que são processos operacionais" ou "acabo de descobrir que eu não sei fazer análise de conteúdo", emanadas dos alunos durante o debate nos pequenos grupos ou durante as discussões compartilhadas no grande grupo. Além dessa tomada de consciência sobre o quê os alunos sabiam ou não, estes também pareciam ter ciência do quanto estavam em dia ou atrasados com os conteúdos da próxima entrega.

Os alunos faziam anotações nas folhas guia constantemente, tanto durante os debates no pequeno grupo, quanto nos debates no grande grupo e, também, quando do fechamento feito pelo professor. Muitos alunos fizeram anotações nos seus projetos de pesquisa, com dicas de ajustes necessários. Havia muita atenção dos alunos durante o debate no grande grupo, bem como às considerações e fechamentos do professor. Por outro lado, o número de orientações individuais com alunos, discutindo dúvidas específicas sobre a sua empresa, diminuiu em muito, uma vez que a maioria das questões era resolvida durante o debate no grande grupo ou no fechamento do tema pelo professor. Ao se comparar os indicadores acadêmicos desta com outras turmas se verificou uma maior pontualidade na chegada dos alunos às aulas, percebendo-se maior envolvimento.

Alguns problemas, entretanto, surgiram durante a aplicação da técnica. Por exemplo, a solicitação de que cada grupo apresentasse um relatório do debate (pequeno grupo) ao final da aula não teve adesão, mesmo valendo nota. Os alunos manifestaram que preferiam fazer anotações nos seus trabalhos a emitir um relatório sobre a discussão. Com isso, a nota destinada aos relatórios (Io\%) foi redistribuída para outras avaliações. Às vezes, nenhum integrante do grupo tinha o referencial teórico (projeto) para consultar um conceito.

Embora raros, ocorreram casos de alunos que se limitavam a ouvir os outros ou não participavam do debate, ficando junto aos celulares ou notebooks. Nessas situações, o professor fazia uma intervenção, convidandoos a voltar ao debate. Por outro lado, alunos mais dedicados acabaram compondo alguns grupos "fechados", procurando evitar os que não desejavam participar de fato. 
A Figura 4 mostra a aplicação do TBL na turma de TCC I. A imagem da esquerda apresenta os alunos durante o debate nos pequenos grupos e, na imagem da direita, cada representante dos grupos aparece fazendo um resumo no quadro sobre seus achados, antes da discussão no grande grupo.

Figura 4 Aplicação da metodologia TBL na turma de TCC I da Administração

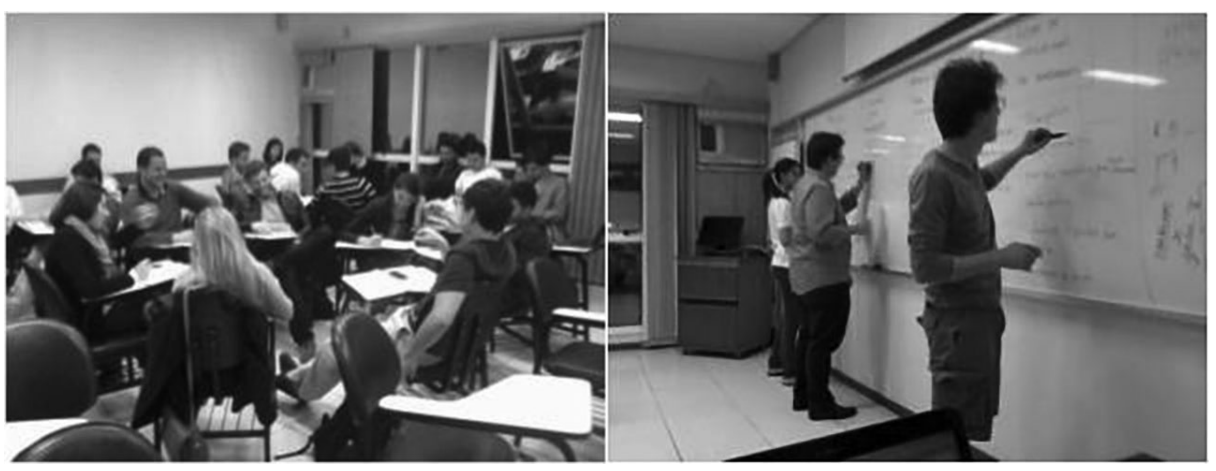

Após o uso da metodologia ativa durante as aulas de aplicação de conceitos, foi aplicado o questionário (vide Anexo I), solicitando-se que os alunos refletissem sobre a experiência e expressassem suas opiniões por meio do questionário. Tabuladas as respostas, se procedeu à análise estatística destas, sendo que a Tabela 4 apresenta as médias, a mediana e as margens de erro das respostas, com $95 \%$ de confiança.

Tabela 4 Estatística descritiva das respostas dos alunos de TCC I

\begin{tabular}{|lcccccccccccc|} 
Variável & $\mathbf{Q 1}$ & $\mathbf{Q 2}$ & $\mathbf{Q 3}$ & $\mathbf{Q 4}$ & $\mathbf{Q 5}$ & $\mathbf{Q 6}$ & $\mathbf{Q 7}$ & $\mathbf{Q 8}$ & $\mathbf{Q 9}$ & $\mathbf{Q 1 0}$ & $\mathbf{Q 1 1}$ & Q12 \\
\hline Média & 3,26 & 3,58 & 2,00 & 2,26 & 3,58 & 3,11 & 1,37 & 2,05 & 1,26 & 2,00 & 3,00 & 3,47 \\
\hline Mediana & 4,00 & 4,00 & 1,00 & 2,00 & 4,00 & 3,00 & 1,00 & 2,00 & 1,00 & 2,00 & 3,00 & 4,00 \\
\hline Margem de erro(95\%) & 0,72 & 0,61 & 0,60 & 0,72 & 0,63 & 0,60 & 0,33 & 0,63 & 0,31 & 0,45 & 0,77 & 0,61 \\
\hline
\end{tabular}

De forma semelhante à análise da outra disciplina, foram destacadas na Tabela 4 as maiores e as menores médias do conjunto de entrevistas realizadas. Um comportamento idêntico ao da disciplina de Pesquisa III ocorreu nessa turma, com a maioria dos alunos preferindo um feedback do 
professor do que do colega (Q9), fato consistente com o resultado da questão 7 (Q7), por meio da qual disseram que o fechamento feito pelo professor não pode ser dispensado, bem como com a questão I (QI), em que a orientação do professor é preferida em relação ao debate com o grupo.

Ainda de forma semelhante à turma de Pesquisa III, a maioria dos alunos disse que a discussão no grupo permitiu ter consciência sobre o quanto realmente sabia sobre o assunto trabalhado (Q2). Um aspecto específico que surgiu na turma de TCCI foi que esta considerou que o ideal seria redigir o item em estudo imediatamente após a discussão em aula (Q5). Finalmente, como avaliação geral, é importante destacar que a maioria gostou da abordagem Team-Based Learning (TBL) (QI2).

Assim como na disciplina de Pesquisa III, também na de TCC I foi feita uma análise de clusters. A Tabela 5 mostra o resultado da análise de clusters para a turma de TCC I, apresentando, além da média global, as médias por questão em cada subgrupo identificado.

Tabela 5 Média global e por subgrupo oriundas da análise de cluster na turma de TCC I

\begin{tabular}{|lllll|}
\hline Variável & Cluster 1 & Cluster 2 & Cluster 3 & Média Geral \\
\hline Q1 & 4,1 & 2,0 & 2,8 & 3,3 \\
\hline Q2 & 3,3 & 4,6 & 3,0 & 3,6 \\
\hline Q3 & 2,6 & 1,6 & 1,0 & 2,0 \\
\hline Q4 & 1,3 & 2,2 & 4,8 & 2,3 \\
\hline Q5 & 3,2 & 3,4 & 4,8 & 3,6 \\
\hline Q6 & 2,6 & 4,4 & 2,8 & 3,1 \\
\hline Q7 & 1,4 & 1,6 & 1,0 & 1,4 \\
\hline Q8 & 1,3 & 3,0 & 2,8 & 2,1 \\
\hline Q9 & 1,0 & 1,6 & 1,5 & 1,3 \\
\hline Q10 & 1,8 & 2,0 & 2,5 & 2,0 \\
\hline Q11 & 2,6 & 2,2 & 5,0 & 3,0 \\
\hline Q12 & 3,1 & 4,6 & 3,0 & 3,5 \\
\hline
\end{tabular}

Como é possível observar, também nessa turma todas as variáveis contribuíram para distinção do comportamento dos subgrupos (clusters). 
Com o intuito de facilitar a interpretação dos resultados e melhor caracterizar cada subgrupo, foi elaborado o Quadro 4, registrando-se somente as opiniões significativamente divergentes da média global.

Quadro 4 Descrição do perfil de cada subgrupo com base no questionário para a turma de TCC I

\begin{tabular}{|c|c|c|}
\hline Perfil do Cluster 1 & Perfil do Cluster 2 & Perfil do Cluster 3 \\
\hline $\begin{array}{l}\text { Prefere orientação individual a } \\
\text { debater com o grupo. }\end{array}$ & $\begin{array}{l}\text { Prefere debater com o grupo a } \\
\text { uma orientação individual. }\end{array}$ & $\begin{array}{l}\text { Considera que a discussão no } \\
\text { grupo não contribuiu para } \\
\text { tomar consciência sobre o quê } \\
\text { sabia de fato. }\end{array}$ \\
\hline $\begin{array}{l}\text { Considera que os estudos } \\
\text { prévios que fez são suficientes } \\
\text { para o debate. }\end{array}$ & $\begin{array}{l}\text { Considera que discussão no } \\
\text { grupo permitiu ao aluno tomar } \\
\text { consciência sobre o quê sabia } \\
\text { de fato. }\end{array}$ & $\begin{array}{l}\text { Não considera que os estudos } \\
\text { prévios que fez são suficientes } \\
\text { para o debate. }\end{array}$ \\
\hline $\begin{array}{l}\text { Prefere não ter que entregar ao } \\
\text { professor um relatório sobre o } \\
\text { debate. }\end{array}$ & $\begin{array}{l}\text { Acredita ter aprendido muito } \\
\text { com os colegas. }\end{array}$ & $\begin{array}{l}\text { Prefere ter que entregar ao } \\
\text { professor um relatório sobre o } \\
\text { debate. }\end{array}$ \\
\hline $\begin{array}{l}\text { Não acredita ter aprendido com } \\
\text { os colegas no debate em grupo. }\end{array}$ & $\begin{array}{l}\text { Acredita que em grupo aprende } \\
\text { mais do que com o professor. }\end{array}$ & $\begin{array}{l}\text { Gostaria de redigir o capítulo do } \\
\text { projeto imediatamente após a } \\
\text { discussão com o grupo. }\end{array}$ \\
\hline $\begin{array}{l}\text { Acredita que aprende mais com } \\
\text { o professor do que com o grupo. }\end{array}$ & $\begin{array}{l}\text { Não crê que a entrega do item } \\
\text { do plano ao final do debate gera } \\
\text { maior aprendizado. }\end{array}$ & $\begin{array}{l}\text { Considera importante o } \\
\text { fechamento por parte do } \\
\text { professor. }\end{array}$ \\
\hline \multirow[t]{2}{*}{$\begin{array}{l}\text { Prefere um feedback do } \\
\text { professor do que de um colega. }\end{array}$} & $\begin{array}{l}\text { É o que mais gostou da } \\
\text { abordagem TBL. }\end{array}$ & $\begin{array}{l}\text { Considera que o debate no } \\
\text { pequeno grupo é suficiente, } \\
\text { não sendo necessário o debate } \\
\text { no grande grupo. }\end{array}$ \\
\hline & & $\begin{array}{l}\text { Acredita que aprenderia mais se } \\
\text { tivesse que entregar a redação } \\
\text { do item no final da aula. }\end{array}$ \\
\hline
\end{tabular}

Ao se considerar as afirmativas relacionadas ao cluster I, se nota claramente que estes alunos parecem preferir o estilo tradicional de ensino e aprendizagem, com o professor exercendo um papel de condutor e de fonte mais confiável de informação do que os colegas. Portanto, não acredita ter aprendido muito com os colegas e gostaria de uma orientação individual. Esse perfil é praticamente o mesmo daquele encontrado no cluster 3, da turma de Pesquisa III. Assim sendo se pode adotar também o nome sugerido de "Tradicional". 
O perfil do cluster 2, por sua vez, parecer ser exatamente o oposto do cluster I. O aluno do cluster 2 prefere claramente debater com o grupo a ter uma orientação individual, além de acreditar ter aprendido com os colegas. Apesar de ter aprendido, não vê necessidade de redigir o capítulo do plano imediatamente, possivelmente desejando refletir melhor antes de formalizar suas ideias. Naturalmente, foi o grupo que mais gostou da abordagem TBL, sendo que, por analogia aos nomes da disciplina de Pesquisa III, esse agrupamento 2 poderia ser chamado também de "Colaborativo". Evidenciase, novamente, que esse grupo está alinhado com a metodologia ativa, uma vez que, como defende Mazur (2015), desloca-se o eixo principal da responsabilidade pelo processo de aprendizagem do professor para o aluno.

No último cluster (3) se apresenta um perfil fortemente ligado à execução das tarefas relacionadas tanto ao TBL quanto ao trabalho de conclusão em si. Esse grupo de alunos manifestou preferência por realizar todas as tarefas listadas, o mais rapidamente possível e de maneira formal. Assim, disse que aprenderia mais se fosse necessário entregar um relatório ao professor, que o ideal seria redigir o capítulo imediatamente após a discussão com o grupo e, se possível, até o final da aula. Preza, portanto, por objetividade, mencionando que bastaria a discussão no pequeno grupo, seguida do fechamento por parte do professor. Este grupo, portanto, tem um perfil alinhado ao grupo I da turma anterior, podendo-se adotar o nome de "Prático", no sentido de prontamente resolver os problemas e realizar as tarefas necessárias.

Com base nos resultados apresentados aqui e anteriormente (aplicação na disciplina de Pesquisa III), se passa à etapa de desdobramento dos achados da pesquisa. 


\section{CONSIDERAÇÕES FINAIS}

O presente artigo buscou apresentar uma experiência de uso da metodologia Team-Based Learning (TBL) em disciplinas de apoio ao planejamento e execução de trabalhos de conclusão de curso. Além de descrever os experimentos realizados, apresentou a avaliação dos alunos quanto à validade da metodologia de ensino, bem como suas percepções em relação à aprendizagem desenvolvida.

Nesse sentido, apesar de desenvolvida em duas turmas de cursos diferentes (Publicidade e Propaganda e Administração de Empresas) e em estágios diferentes do curso ( $8^{\circ}$ e $9^{\circ}$ semestre, respectivamente), ambos apresentaram resultados muito semelhantes. Tanto na disciplina de Pesquisa III quanto na de TCC I, percebe-se que a maioria dos alunos disse preferir um feedback do professor do que do colega e reforçam esse entendimento na medida em que afirmam ser necessário o fechamento feito pelo professor. Possivelmente esse ainda é um resquício de muitos anos de uma abordagem tradicional de ensino, na qual a palavra final sobre o que está certo ou errado é dada pelo professor. Isto foi reforçado pela manifestação de que a orientação do professor é preferida em relação ao debate com o grupo, reforçando o estilo de ensino e aprendizagem tradicional, onde o professor ensina, conduz e valida o conhecimento.

Por outro lado, a maioria dos alunos entende que a discussão no grupo permitiu ter consciência sobre o quanto realmente eles sabiam sobre o assunto trabalhado. Esta é uma das grandes vantagens do processo de debate entre os alunos, uma vez que, na troca de opiniões sobre um tema é possível perceber-se mais ou menos colaborativo. Em consequência, há um dar-se conta do grau de aprofundamento e domínio sobre conteúdos que, supostamente, já deveriam estar dominados, uma vez que houve um preparo prévio por meio de leituras ou acesso a outros recursos. $\mathrm{O}$ aluno tem a oportunidade, inclusive, de validar os seus métodos atuais de estudos, verificando se as leituras, na forma que tem sido feitas, são suficientes para embasar uma discussão mais aprofundada sobre um tema.

Alguns poucos pontos foram distintos entre as duas turmas. Por exemplo, na disciplina de Pesquisa III os alunos disseram preferir a discussão somente 
no pequeno grupo, dispensando a discussão no grande grupo. Já na turma de TCC I houve uma manifestação de preferência por redigir o item em estudo imediatamente após a discussão em aula. De qualquer modo, é válido ressaltar que a maioria dos alunos gostou da abordagem Team-Based Learning (твL).

No que diz respeito aos achados intragrupos, identificaram-se, em essência, os mesmos três perfis de alunos nas duas turmas estudadas: o tradicional, o colaborativo e o prático. O "aluno tradicional" parece ter uma postura mais passiva, isto é, de recepção do conhecimento (ensino centrado no professor). É o grupo que prefere a orientação individual a debater com o grupo, não ter que entregar relatórios ao professor sobre o debate e não reconhecendo o grupo como potencializador da construção do seu conhecimento.

Já o "aluno colaborativo" desenvolve um processo totalmente oposto ao "aluno tradicional", isto é, tem um papel ativo na construção do conhecimento, mostrando-se totalmente aberto à abordagem TBL (ensino centrado no aluno). Trata-se de um grupo de alunos que tem ciência do seu papel, e que vai, por exemplo, propor a forma final para o produto da sua reflexão. Sente-se, portanto, à vontade para escolher os caminhos e os recursos para aprender. Destaca-se que esse perfil entende que a discussão no grupo permitiu uma tomada de consciência sobre o quê sabia de fato a respeito do assunto estudado. Além disso, acredita ter aprendido muito com os colegas, inclusive revelando que, em grupo, aprende mais do que com o professor. Esse perfil parece entender a principal proposta de Michaelsen, Knight e Fink (2002) que diz que times ou equipes são diferentes de grupos. Times são caracterizados por um elevado nível de compromisso individual para o bem-estar do grupo e de um elevado nível de confiança entre os membros.

Há também outro perfil identificado, o do "aluno prático", o qual prefere focar no desenvolvimento da tarefa, sem muitos debates, mas ainda sendo tradicional quanto à entrega do trabalho ao professor. Os alunos com esse perfil preferem entregar ao professor um relatório sobre o debate e redigir o capítulo do projeto imediatamente após a discussão com o grupo, acreditando que aprenderiam mais se tivessem que entregar a redação do 
item no final da aula. É interessante notar que esse grupo não foi contrário à metodologia TBL, desejando apenas que os seus desdobramentos fossem formalizados mais rapidamente.

Nesse contexto, os autores desse artigo pretendem continuar utilizando a metodologia TBL nos próximos semestres, analisando os resultados de forma comparativa com as metodologias tradicionais que eram adotadas anteriormente. Além disso, pretende-se realizar alguns ajustes na aplicação TBL, passando a incluir formalmente as etapas de validação individual antes dos debates em grupo.

Uma oportunidade a ser testada e que já está com ensaios em andamento, é a conciliação da metodologia TBL com outra, chamada de Peer Evaluation. Esta consiste em um processo de avaliação entre pares (alunos) e permitirá, possivelmente, uma melhor forma de fazer as avaliações dos resultados dos grupos. Michaelsen, Knight e Fink (2002) sugerem que os integrantes da equipe também são capazes de dar feedback aos colegas, inclusive de maneira formal. Essa ideia de ajuste é fruto das observações realizadas pelos professores durante a aplicação da metodologia TBL e parece ser aplicável na medida em que os alunos se apropriam mais e melhor da metodologia de trabalho em grupo.

Sugestões como essa, bem como outras melhorias no processo de aplicação da metodologia, denotam as vantagens do TBL também para os professores. Na medida em que os alunos conduzem, de maneira mais autônoma, o processo de aprendizagem, mais tempo sobra para o professor observar, ouvir e refletir sobre o processo de ensino. Mais uma vez, vêm à luz as grandes vantagens da metodologia de aprendizagem baseada em equipes: não só ganham os alunos, por se apropriarem do processo de aprendizagem, como ganham também os professores, desempenhando sua função maior que é a de prover as condições para uma aprendizagem prazerosa e significativa. 


\section{REFERÊNCIAS}

ABNT - Associação Brasileira de Normas Técnicas. NBR 10520: informação e documentação. Rio de Janeiro: ABNT, 2002.

BORN, R. Construindo o plano estratégico. Porto Alegre: Sulina, 2009.

BUCK Institute for Education. Aprendizagem baseada em projetos: guia para professores de ensino fundamental e médio. Porto Alegre: Artmed, 2008.

CECCONELlO, A.; AJZENTAL, A. A construção do plano de negócio. São Paulo: Saraiva, 2008.

DUNN, R. Understanding the Dunn and Dunn learning styles model and the need for individual diagnosis and prescription. Journal of Reading, Writing and Learning Disabilities, v. 6, p. 223-247, 1990.

INSTITUIÇÃO DOS AUTORES. Regulamento do trabalho de conclusão de curso - TCC: administração de empresas e publicidade e propaganda. São Paulo: Instituição dos Autores, 2014.

FERREIRA JÚNIOR, C. Guia do trabalho cientifico: do projeto à redação final: monografia, dissertação e tese. São Paulo: Contexto, 2011.

GOPALAN, C.; FOX, D.; GAEBELEIN, C. Effect of an individual readiness assurance test on a team readiness assurance test in the team-based learning of physiology. Adv Physiol Educ, v. 37, n. 1, p. 61-4, 2013.

MALHOTRA, N. Pesquisa de marketing: uma orientação aplicada. Porto Alegre: Bookman, 2001.

MARCONI; A.; LAKATOS, E. M. Técnicas de pesquisa: planejamento e execução de pesquisas, amostragens e técnicas de pesquisa, de elaboração, análise e de interpretação de dados. São Paulo: Atlas, 2008.

MATTAR, F. N. Pesquisa de Marketing. Edição Compacta. São Paulo: Atlas, 1999.

MAZUR, E. Peer instruction: a revolução da aprendizagem ativa. Porto Alegre: Penso, 2015.

MELO, B.; SANT'ANA, G. A prática da metodologia ativa: compreensão dos discentes enquanto autores do processo ensino-aprendizagem. Comunicação em Ciências da Saúde, 2012.

MICHAELSEN, L.; KNIGHT, A.; FINK, D. Team-Based Learning: a transformative use of small groups. Westport, CT: Praeger, 2002.

MIZUKAMI, M. da G. Ensino: as abordagens do processo. São Paulo: EPU, 1986.

NEHER, C. O trabalho de conclusão de curso: orientações e critérios para uma boa nota. E-book. 2002.

ROESCH, S. M. Projetos de estágio do curso de Administração: guia para pesquisas, projetos, estágios e trabalhos de conclusão de curso. São Paulo: Atlas, 1996. 
SEVERINO, A. J. Metodologia do trabalho cientifico. São Paulo: Cortez, 2009.

SIMONSON, S. Making students do the thinking: team-based learning in a laboratory course. Adv Physiol Educ, v. 38, n. 1, p. 49-55, 2014.

STUMPF, I. M. Pesquisa bibliográfica. In: DUARTE, J.; BARROS, A. Métodos e técnicas de pesquisa em comunicação. São Paulo: Atlas, 2005.

TEIXEIRA, G. O estado da arte de aprendizagem centrada no aluno em administração. Revista de Administração da USP, v. 20, n. 2, p. 56-62, 1985. 


\section{ANEXO I - QUESTIONÁRIO TEAM-BASED LEARNING}

A abordagem de Team-Based Learning propõe que o aprendizado pode ocorrer pela troca de conhecimentos e visões sobre um determinado tema entre componentes de um grupo. Se os integrantes do grupo estiverem preparados para o debate, conceitos poderão ser esclarecidos e aplicações práticas poderão ser propostas. Considerando essa abordagem da disciplina de avalie as afirmações a seguir e se posicione entre o conceito " $\mathrm{",} \mathrm{Discordo} \mathrm{totalmente} \mathrm{e} \mathrm{o} \mathrm{"} 5$ ", Concordo totalmente.

\begin{tabular}{|c|c|c|c|c|c|}
\hline $\begin{array}{l}\text { 1. Eu prefiro uma orientação individual sobre um tema, ainda que rápida, a ter } \\
\text { que debater sobre ele com um grupo de colegas. }\end{array}$ & $\square$ & $\square$ & $\square$ & $\square$ & $\begin{array}{l}\square \\
5\end{array}$ \\
\hline $\begin{array}{l}\text { 2. A discussão no grupo me permitiu ter consciência do quanto eu realmente } \\
\text { sabia sobre um determinado assunto do trabalho. }\end{array}$ & $\square$ & $\square$ & $\square$ & $\square$ & 5 \\
\hline $\begin{array}{l}\text { 3. Considero que os estudos que fiz na disciplina de __ são } \\
\text { suficientes para que eu possa ensinar um colega sobre esses assuntos. }\end{array}$ & $\square$ & $\square$ & $\square$ & $\square$ & 5 \\
\hline regar ao professor & $\square$ & $\square$ & $\square$ & $\square$ & 5 \\
\hline $\begin{array}{l}\text { 5. O ideal é que eu pudesse redigir o capítulo do meu projeto imediatamente } \\
\text { após a discussão com o grupo, usando um notebook ou o laboratório de } \\
\text { informática. }\end{array}$ & $\square$ & $\begin{array}{l}\square \\
2\end{array}$ & $\square$ & $\begin{array}{r}\square \\
4\end{array}$ & $\begin{array}{l}\square \\
5\end{array}$ \\
\hline ero que aprendi muito com os meus colegas durante os debates no & $\square$ & $\square$ & $\begin{array}{l}\square \\
3\end{array}$ & $\begin{array}{r}\square \\
4\end{array}$ & $\begin{array}{l}\square \\
5\end{array}$ \\
\hline $\begin{array}{l}\text { 7. Embora tenha sido útil, considero que o fechamento feito pelo professor } \\
\text { pode ser dispensado, uma vez que o mais importante já foi debatido pelo } \\
\text { grupo. }\end{array}$ & $\begin{array}{l}\square \\
1\end{array}$ & $\begin{array}{l}\square \\
2\end{array}$ & $\begin{array}{l}\square \\
3\end{array}$ & $\begin{array}{r}\square \\
4\end{array}$ & $\begin{array}{l}\square \\
5\end{array}$ \\
\hline 8. Em grupo eu aprendo mais do que conversando com o professor. & $\begin{array}{l}\square \\
1\end{array}$ & $\begin{array}{l}\square \\
2\end{array}$ & $\begin{array}{l}\square \\
3\end{array}$ & $\begin{array}{l}\square \\
4\end{array}$ & $\begin{array}{l}\square \\
5\end{array}$ \\
\hline 9. Prefiro um feedback de um colega do que do professor. & $\begin{array}{l}\square \\
1\end{array}$ & $\begin{array}{l}\square \\
2\end{array}$ & $\begin{array}{l}\square \\
3\end{array}$ & $\begin{array}{r}\square \\
4\end{array}$ & $\begin{array}{l}\square \\
5\end{array}$ \\
\hline $\begin{array}{l}\text { 10. Acredito que os debates nos pequenos grupos são suficientes para } \\
\text { garantir a aprendizagem sobre o tema em questão, não sendo necessário } \\
\text { discuti-los no grande grupo. }\end{array}$ & $\begin{array}{l}\square \\
1\end{array}$ & $\begin{array}{l}\square \\
2\end{array}$ & $\begin{array}{l}\square \\
3\end{array}$ & $\begin{array}{l}\square \\
4\end{array}$ & $\begin{array}{l}\square \\
5\end{array}$ \\
\hline $\begin{array}{l}\text { 11. Acho que se eu tivesse que entregar a redação do item em debate ao final } \\
\text { da aula eu aprenderia mais. }\end{array}$ & $\square$ & $\square$ & $\square$ & $\square$ & $\begin{array}{l}\square \\
5\end{array}$ \\
\hline $\begin{array}{l}\text { 12. De modo geral, posso dizer que gostei da abordagem de aprendizagem } \\
\text { baseada em times. }\end{array}$ & $\square$ & $\square$ & $\square$ & $\square$ & $\begin{array}{l}\square \\
5\end{array}$ \\
\hline
\end{tabular}




\title{
DADOS DOS AUTORES
}

\author{
ANI MARI HARTZ* ani.hartz@espm.br \\ Doutora em Comunicação pela UNISINOS \\ Instituição de vinculação: Escola Superior de Propaganda e Marketing-Sul \\ Porto Alegre/RS - Brasil \\ Áreas de interesse em pesquisa: Marketing, comunicação, ensino.
}

${ }^{\star}$ Rua Guilherme Schell, 350 Santo Antônio Porto Alegre/RS 90640-040

\section{GABRIEL VIANNA SCHLATTER gschlatter@espm.br Doutor em Informática na Educação pela UFRGS}

Instituição de vinculação: Escola Superior de Propaganda e Marketing-Sul Porto Alegre/RS - Brasil

Áreas de interesse em pesquisa: Simuladores de negócios, informática na educação e empreendedorismo. 